\title{
A THERMOHYDRODYNAMIC MODEL OF AN ICE SHEET
}

\author{
By M. Ya. Verbitsky and D. V. Chalikov \\ (Leningradskiy otdel, Institut Okeanologii im. P. P. Shirshova, Pervaya Liniya 30, \\ I99053 Leningrad, U.S.S.R.)
}

\begin{abstract}
The purpose of this paper is to consider an ice-sheet model based on joint solution to the dynamic equations and equations of heat conductivity in which the surface relief is one of the unknown functions. The proposed model is applicable to calculations of the Antarctic ice sheet. Results of a numerical experiment for present values of the temperature of the ice surface and precipitation as well as for their separate and simultaneous increase by 2,4 , or $6 \mathrm{deg}$ and 10,20 , or $30 \%$ are given.

RÉsumÉ. Un modèle thermodynamique de calotte glaciaire. Le but de cet article est d'examiner un modèle de calotte glaciaire basé sur la solution conjointe des équations dynamiques et des équations de conductivité thermique dans lesquelles le relief de la surface est l'une des fonctions inconnues. Le modèle proposé est applicable au calcul de la calotte glaciaire antarctique. On donne les résultats d'un essai numérique du modèle pour les conditions actuelles de température de la surface de la glace et de précipitations ainsi que dans l'hypothèse de l'accroissement simultané ou séparé de l'un ou l'autre paramètre de 2, 4, ou 6 deg et de 10, 20 , ou $30 \%$.

Zúsammenfassung. Ein thermohydrodynamisches Model eines Eisschildes. Das Ziel dieser Arbeit ist die Entwicklung eines Eisschildmodelles, das auf der gemeinsamen Lösung der dynamischen Gleichungen und der Wärmeleitungsgleichungen beruht und in dem das Oberflächenrelief eine der unbekannten Funktionen bildet. Das vorgeschlagene Modell lässt sich bei Berechnungen für den antarktischen Eisschild anwenden. Es werden Ergebnisse einer Versuchsrechnung für derzeitige Werte der Temperatur an der Eisoberfläche und des Niederschlags sowohl bei getrenntem wie gleichzeitigem Anwachsen um 2, 4, 6 Grad bzw. 10, 20,
$30 \%$ mitgeteilt.
\end{abstract}

Theoretical investigations of ice sheets usually reduce to calculations of the velocity field and temperature using data on the relief of the surface and bed taking into account the horizontal distribution of accumulation, ablation, surface temperature, and geothermal heat flux (see, e.g. Budd, r969; Budd and others, [1970]). A disadvantage of this prediction approach is that it does not allow simulation of the mechanism of production of the ice sheet and its evolution. In this paper we consider a more complete model of a large flat ice sheet in which the surface relief is an unknown function.

We consider for simplicity an axisymmetric stationary ice sheet which spreads over a flat bed of radius $R$. We assign an ice accumulation which is a function $a(r)$ of radius $r$ on the surface of the glacier, which is the difference between precipitation and melting. It follows from the condition of stationarity that in an infinitely small radius in the vicinity of $r=R$ there occurs a sink of excess mass whose value is defined by the difference between the integral mass influx and melting at the ice-sheet surface. It is assumed that this is realized by the production of icebergs. A geothermal heat flux is assigned at the lower boundary of the glacier. It is necessary to define the surface relief and distribution of the velocity and temperature in the ice. This formulation of the problem allows us to investigate the evolution of an ice sheet at time intervals much larger than the characteristic relaxation time of the stationary regime. This may be useful, for example, in studying the evolution of Antarctic glaciation during the last 80 million years when there occurred significant variations in air temperature and precipitation caused by the drift of continents and changes in the oceanic circulation of the Southern Hemisphere.

The theoretical model is based on the continuity equation

$$
\frac{\mathrm{I}}{r} \frac{\partial}{\partial r}(r U)+\frac{\partial W}{\partial z}=\mathrm{o}
$$

the equation of mass conservation at the upper boundary

$$
W_{h}=U_{h} \frac{\partial h}{\partial r}-a,
$$


and the equation of heat conduction

$$
U \frac{\partial T}{\partial r}+W \frac{\partial T}{\partial z}=k \frac{\partial^{2} T}{\partial z^{2}}+\frac{1}{\rho c} \tau \frac{\partial U}{\partial z} .
$$

In Equations ( 1 )-(3), $z$ is the vertical and $r$ the horizontal coordinate (the origin of the coordinates is placed in the centre of the glacier base), $U$ and $W$ are the horizontal and vertical velocity components, $U_{h}, W_{h}$ are their values at the surface $z=h, k, \rho$, and $c$ are the thermal conductivity, density, and specific heat capacity of the ice, and $\tau$ is the horizontal component of tangential stress.

Equations ( 1 )-(3) are used together with the flow law in the following form (Grigoryan and others, 1976):

$$
\frac{\mathrm{I}}{2} \frac{\partial U}{\partial z}=K \tau^{n} \exp \left[-\kappa\left(\frac{T_{0}}{T}-\mathrm{I}\right)\right],
$$

where $\tau=-\rho g(h-z)(\partial h / \partial r)$, obtained on the assumption that the pressure-gradient force arising due to surface inclination is balanced by viscous stress (Nye's (I95I) well-known expression). In Equation (4), $T_{0}$ is the absolute temperature of ice melting, $K, n$, and $\kappa$ are parameters of the flow law, and $g$ is the gravitational acceleration. Comparative analysis of the component value of the deformation-rate tensor and complete solution to the equations of motion for stresses have been obtained by Grigoryan and others (1976). The simple relations for $\tau$ and deformation velocity which we used in Equations (3) and (4) are the simplest case of this solution for a flat base and for $R \gg h$.

We introduce the vertical velocity scale $\tilde{W}=a$ and, according to Equation ( $\mathrm{I}$ ), the horizontal velocity scale $\tilde{U}=a R / h$. It follows from Equation (2) that a glacier of thickness $h$ has a characteristic time scale $t_{\mathrm{e}}=h / a$ due to accumulation and ablation. The duration of the passage of an ice particle from the centre of the glacier to its edge has the same order of magnitude as the time scale of relaxation of the stationary temperature regime in the ice sheet due to advective terms. A similar diffusive scale is defined by the expression $t_{\mathrm{d}}=h^{2} / k$. For the Antarctic ice sheet, $R \approx 2 \times 10^{6} \mathrm{~m}, h \approx 2 \times 10^{3} \mathrm{~m}, a \approx 3 \times 10^{-9} \mathrm{~m} \mathrm{~s}^{-1}$ such that $\tilde{U} \approx 3 \times 10^{-6} \mathrm{~m} \mathrm{~s}^{-1}$, and $t_{\mathrm{e}} \approx 0.7 \times 10^{12} \mathrm{~s}$ (about 20000 years). Assuming that $k=\mathrm{IO}^{-6} \mathrm{~m}^{2} \mathrm{~s}^{-1}$ we have $t_{\mathrm{d}} \approx 4 \times \mathrm{IO}^{12} \mathrm{~s}$. The difference in the estimates $t_{\mathrm{d}}$ and $t_{\mathrm{e}}$ by one order of magnitude indicates a subordinate role of heat conductivity compared to vertical advection. It is clear that the horizontal diffusive heat flux which is not taken into account in Equation (3) is altogether insignificant. We also consider the glacier dynamic relaxation scale $t_{\mathrm{m}}$ defined from Equation $(4)$ as $t_{\mathrm{m}} \approx \rho a R\left(\frac{K h^{2}}{a R}\right)^{\mathrm{I} / n}$. Because of the large ice viscosity, $t_{\mathrm{m}}$ appears of order $1^{-3} \mathrm{~s}$, i.e. glacier dynamic relaxation occurs practically instantaneously, which justifies our choice of the motion equation of the form of Equation (4). Application of Equation (3) in the stationary form at time intervals of the order of 2000 years may lead to errors in determining the temperature distribution.

The boundary conditions are assumed to be $h=\mathrm{o}$ for $r=R$, and temperature distribution at the glacier surface $T_{h}$ is taken to be known, as is the geothermal heat flux $-\left.\lambda \frac{\partial T}{\partial z}\right|_{z=0}=Q$, $\lambda \equiv k \rho c$. If the temperature in the neighbourhood of the bed rises to the melting point of ice $T_{0}$, then it is assumed that $T=T_{0}$ and $-\left.\lambda \frac{\partial T}{\partial z}\right|_{z=0}=Q+v \rho W_{0}$ where $v$ is the latent heat of melting ice and $W_{0}$ is the velocity of bottom melting. Finally, velocity is assumed to vanish, $U=0$, near the glacier bed. The latter condition may be not quite accurate if any ice melting occurs near the bed; however, since all parameters of the problem are known to be very approximate, taking this effect into account would appear to be premature. 
We now start deriving the model equations. We integrate Equation ( $\mathrm{r}$ ) from o to $h$ and, using the kinematic condition at the free surface Equation (2), obtain the obvious net mass conservation

$$
\int_{0}^{h} U \mathrm{~d} z=\frac{\mathrm{I}}{r} \int_{0}^{r} a r \mathrm{~d} r
$$

Using Equation (I) we reduce Equation (3) to divergent form, integrate it from o to $h$ on $z$ and, once again using Equation (2) and the boundary conditions for Equation (2), we obtain the integral equation of internal thermal heat-energy conservation

$$
\int_{0}^{h} U T \mathrm{~d} z=\frac{\mathrm{I}}{r} \int_{0}^{r} A r \mathrm{~d} r
$$

where $A$ is a function describing the distribution of inner and outer heat sources

$$
A=a T_{h}+\frac{\mathrm{I}}{\rho c}\left(Q-Q_{h}\right)+\frac{\mathrm{I}}{\rho c} \int_{0}^{h} \tau \frac{\partial U}{\partial z} \mathrm{~d} z .
$$

Here, $Q_{h}=-\left.\lambda \frac{\partial T}{\partial z}\right|_{z=h}$ is the heat flux through the surface $z=h$.

Finally, Equation (4) can be written in the form

$$
U=2 K(\rho g)^{n}\left(-\frac{\partial h}{\partial r}\right)^{n} \int_{0}^{z}(h-z)^{n} \exp \left[-\kappa\left(\frac{T_{0}}{T}-\mathrm{I}\right)\right] \mathrm{d} z .
$$

It can readily be seen that for the case of close to isothermal conditions $T=T^{\star}$ the set of equations reduces to the form (see Budd, r969)

$$
\begin{gathered}
\frac{2 K}{n+2}(\rho g)^{n} \exp \left[-\kappa\left(\frac{T_{0}}{T^{\star}}-\mathrm{I}\right)\right]\left(-\frac{\partial h}{\partial r}\right)^{n} h^{n+2}=\frac{\mathrm{I}}{r} \int_{0}^{r} a r \mathrm{~d} r, \\
h=\left(\frac{2 n+2}{\rho g n}\right)^{n /(2 n+2)}\left(\frac{n+2}{2 K}\right)^{\mathrm{I} /(2 n+2)} \exp \left[\frac{\kappa}{2 n+2}\left(\frac{T_{0}}{T^{\star}}-\mathrm{I}\right)\right] \times \\
\times\left[\int_{r}^{R}\left(\frac{\mathrm{I}}{r} \int_{0}^{r} \operatorname{ard} \mathrm{d}\right)^{\mathrm{I} / n} \mathrm{~d} r\right]^{n /(2 n+2)} .
\end{gathered}
$$

It is interesting to note that Equations (9) and (10) yield a simple relationship between the volumes of the glacier $V_{1}$ and $V_{2}$ at temperatures $T_{1}$ and $T_{2}$

$$
\frac{V_{1}}{V_{2}}=\exp \left[\frac{\kappa T_{0}}{2 n+2}\left(\frac{\mathrm{I}}{T_{1}}-\frac{\mathrm{I}}{T_{2}}\right)\right] .
$$

We describe the technique for solving the problem. Substituting Equation (8) into Equation (5) we obtain the equation

$$
\left(-\frac{\partial h}{\partial r}\right)^{n} \int_{0}^{h} 2 K(\rho g)^{n} \int_{0}^{z}(h-z)^{n} \exp \left[-\kappa\left(\frac{T_{0}}{T}-\mathrm{I}\right)\right] \mathrm{d} z \mathrm{~d} z=\frac{\mathrm{I}}{r} \int_{0}^{r} a r \mathrm{~d} r,
$$


which can be solved using the finite-difference equation

$$
\begin{aligned}
h_{i}=h_{i+1}+\Delta r\left[\int_{0}^{h_{i}} 2 K(\rho g)^{n} \int_{0}^{z}\right. & \left(h_{i}-z\right)^{n} \times \\
& \left.\quad \times \exp \left[-\kappa\left(\frac{T_{0}}{T}-\mathrm{I}\right)\right] \mathrm{d} z \mathrm{~d} z\right]^{-1 / n}\left[\frac{\mathrm{I}}{r} \int_{0}^{r} a r \mathrm{~d} r\right]^{1 / n},
\end{aligned}
$$

where $h_{i}$ and $h_{i_{+1}}$ are values of $h$ at the grid nodes. Several iterations over $h$ are used at each step. We assume the value of $h$ to be a first approximation for vertical averaging of the factor

$$
\begin{gathered}
\exp \left[-\kappa\left(\frac{T_{0}}{T}-\mathrm{I}\right)\right] \\
h=\left(\frac{2 n+2}{\rho g n}\right)^{n /(2 n+2)}\left(\frac{n+2}{2 K}\right)^{\mathrm{I} /(2 n+2)}\left[\int_{r}^{R}\left(\frac{\mathrm{I}}{\mu r} \int_{0}^{r} \operatorname{ar} \mathrm{d} r\right)^{1 / n} \mathrm{~d} r\right]^{n /(2 n+2)},
\end{gathered}
$$

where

$$
\mu=\frac{\mathrm{I}}{h} \int_{0}^{h} \exp \left[-\kappa\left(\frac{T_{0}}{T}-\mathrm{I}\right)\right] \mathrm{d} z .
$$

The velocity field is found using Equation (8).

Taking into account the fact that the flow law parameters for ice are approximately known quantities and that the vertical distribution of temperature in a glacier is a smoothly varying function, we use a parabolic approximation for temperature

$$
T=T_{1}+T_{2} \xi+T_{3} \xi^{2},
$$

where $\xi=z / h$, which, allowing for the boundary conditions, yields

$$
T=T_{\mathrm{I}}-\frac{Q}{\lambda} h \xi+\left(T_{h}-T_{\mathrm{I}}+\frac{Q}{\lambda} h\right) \xi^{2} .
$$

Substituting Equation (16) into Equation (6) gives a differential equation for $T_{\mathrm{I}}$. The simplest situation, however, occurs if one takes into account the fact that the heat flux through the surface $Q_{h}$ is appreciably less than advective flux $a T_{h}$ (see Grigoryan and others, 1976). $T_{\mathrm{I}}$ is defined by

$$
\tau_{\mathrm{I}} \equiv \frac{\frac{\mathrm{I}}{r} \int_{0}^{r} A r \mathrm{~d} r-\int_{0}^{h} U\left[-\frac{Q}{\lambda} h \xi+\left(T_{h}+\frac{Q}{\lambda} h\right) \xi^{2}\right] \mathrm{d} z}{\int_{0}^{h} U\left(\mathrm{I}-\xi^{2}\right) \mathrm{d} z} .
$$

Calculations using the exact equation reveal that $Q_{h}$ is smaller than $a T_{h}$ by two orders of magnitude, on average.

The model presented above was used for simulating the Antarctic ice sheet of radius $R=2 \times 10^{6} \mathrm{~m}$. The calculations are based on precipitation and surface-temperature distributions shown in Figure $\mathrm{I}$ which also gives empirical data from Tolstikov (1966) taken along the profile from Mirny Station towards the centre of spreading of the ice cover of the East Antarctic Continent.

The values of parameters used in the calculations are: $\rho=9^{1} 7 \mathrm{~kg} \mathrm{~m}^{-3}, c=2 \times \mathrm{IO}^{3}$ $\mathrm{J} \mathrm{kg}^{-1} \mathrm{deg}^{-1}, \quad k=\mathrm{I} . \mathrm{I} \times \mathrm{IO}^{-6} \mathrm{~m}^{2} \mathrm{~s}^{-1}, \quad \kappa=2 \mathrm{I} . \mathrm{I}, \quad g=9.8 \mathrm{~m} \mathrm{~s}^{-2}, \quad Q=0.063 \mathrm{~W} \mathrm{~m} \mathrm{~m}^{-2}, \quad T_{0}=$ 273. $15 \mathrm{~K}$. The parameters in the ice flow law are: $n=\mathrm{I}, K=0.3 \times 1 \mathrm{O}^{-13} \mathrm{~m}^{2} \mathrm{~N}^{-1} \mathrm{~s}^{-1}$. 


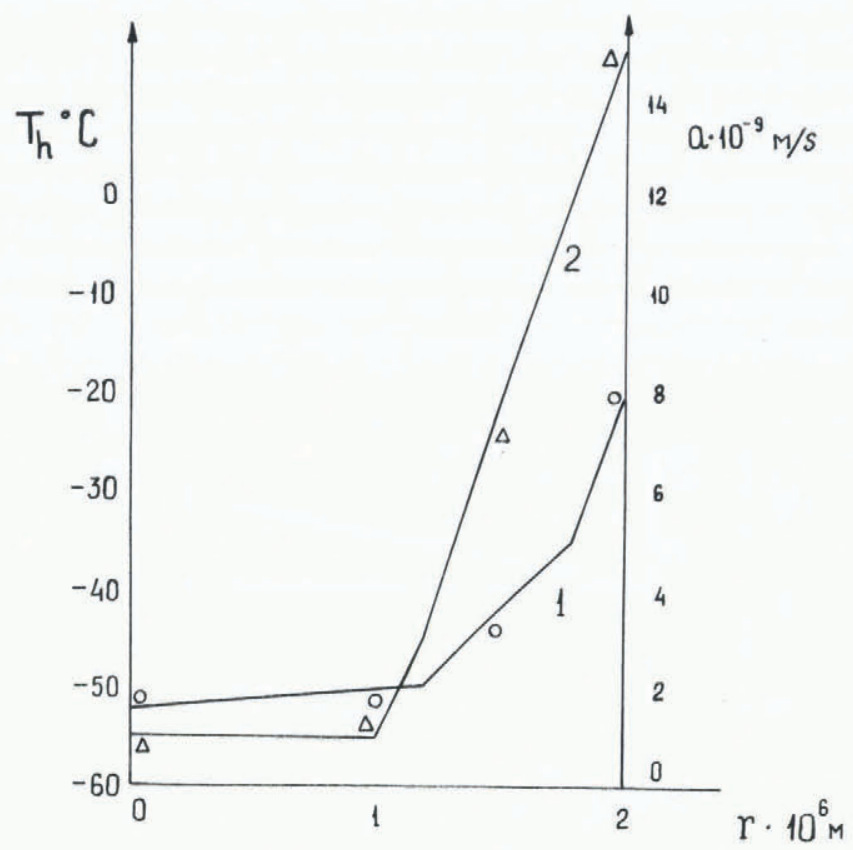

Fig. I. Temperature at the ice surface and accumulation function. $I$-distribution of $T_{h}$ used in the calculation; 2-distribution of a used in the calculation; $O, \triangle$-corresponding empirical data for $T_{h}$ and $a$.

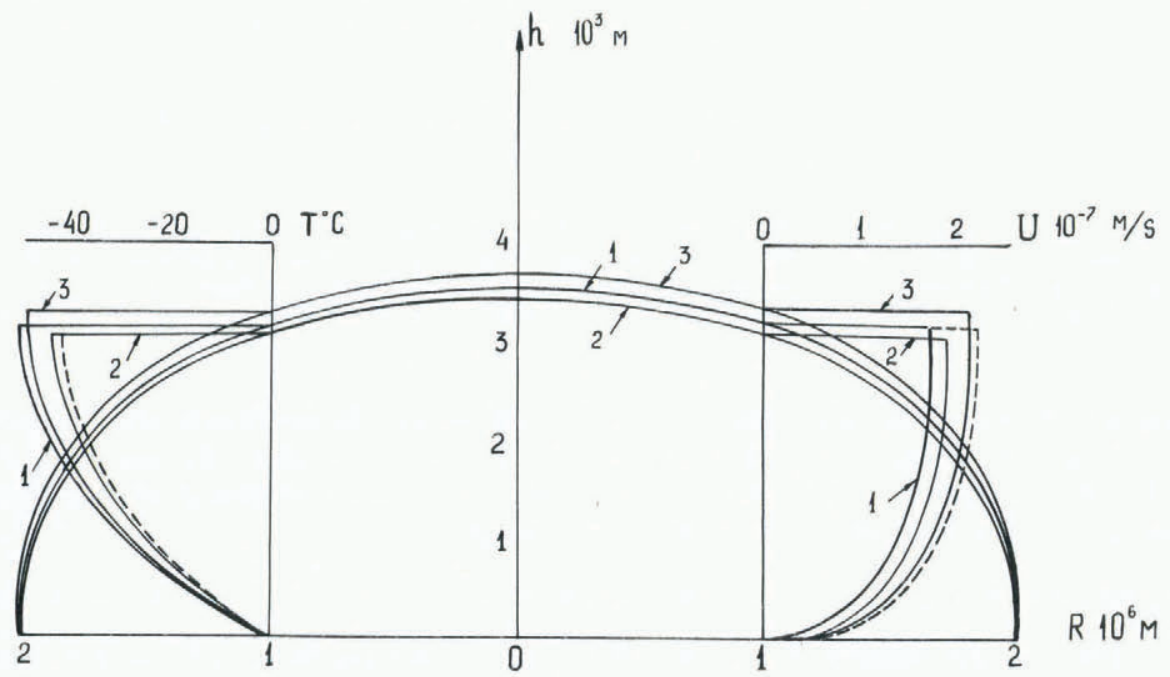

Fig. 2. Glacier surface. The vertical profiles of temperature and horizontal velocity. I-present distribution of the surface temperature and precipitation; 2-if surface temperature is enhanced by $6 \mathrm{deg} ; 3$ - if precipitation is enhanced by $33 \%$ (dashed line indicates velocity and temperature profiles for simultaneous increase in $T_{h}$ by 6 deg and in a by $33 \%$ ). 
Solutions to the equations were obtained not only for present values of the ice surfacetemperature and accumulation $a(r)$, but also for the separate and simultaneous increase in the temperature by 2, 4, or $6 \mathrm{deg}$ and precipitation by 10, 20, or $30 \%$.

The present condition of the Antarctic ice sheet is characterized by the following figures: the thickness of the sheet in the centre, $3600 \mathrm{~m}$; the mean glacier temperature, $-29.4^{\circ} \mathrm{C}$; the conductive heat flux, $7 \times 1 \mathrm{IO}^{1 \mathrm{II}} \mathrm{W}$; the influx of heat is $2 \times 1 \mathrm{IO}^{11} \mathrm{~W}$ due to deformation and $2 \times 10^{13} \mathrm{~W}$ due to precipitation. Figure 2 shows profiles of the ice sheet and temperature and horizontal velocity distribution for the present values of temperature and precipitation and also for precipitation enhanced by $33 \%$ and temperature increased by $6 \mathrm{deg}$. It is interesting to note that for simultaneous changes in the temperature and precipitation, the glacier profile is in practice coincident with the present profile. Figure 3 shows the dependence of the

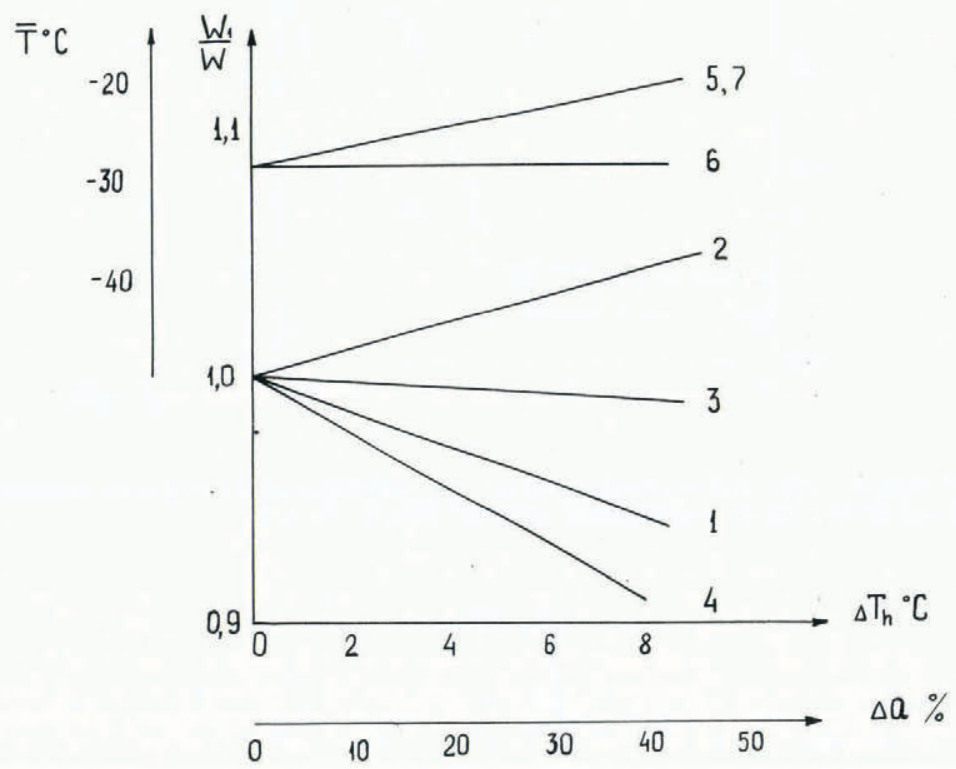

Fig. 3. Dependence of the glacier volume and mean temperature on changes in surface temperature and precipitation. I- dependence of volume on changes in $T_{h} ; 2$-dependence of volume on changes in a; 3 -changes in volume for simultaneous changes in $T_{h}$ and $a ; 4$-dependence of volume on changes in temperature (isothermal model); 5 - dependence of mean temperature $\bar{T}$ on changes in $T_{h} ; 6$-dependence of $\bar{T}$ on changes in $a ; 7$-changes in $\bar{T}$ for simultaneous changes in $T_{h}$ and $a$.

mean temperature and volume of the ice sheet on the surface temperature and ice accumulation both when the value of one of the arguments is fixed and when the two change simultaneously. The stability of the results to changes in the values of flow-law parameters and geothermal flow has been tested by additional calculations.

We also note that, as indicated by analytical investigation, $\left.\frac{\partial h}{\partial r}\right|_{r \rightarrow R} \rightarrow \infty$ (this is shown in Fig. 2). Thus, in the vicinity of $r=R$, the initial set of equations, strictly speaking, is inapplicable. But for a numerical solution this circumstance is of little importance since for $r=R-\Delta r$ the surface slope is already not very great. Therefore, in the solution to Equation (12) we use the only boundary condition: $h=$ o for $r=R$.

MS. received 2 January 1979 and in revised form 24 May 1979 


\section{REFERENCES}

Budd, W. F. I969. The dynamics of ice masses. ANARE Scientific Reports. Ser. A(IV). Glaciology. Publication No. 108.

Budd, W. F., and others. [1970.] The extent of basal melting in Antarctica, by W. [F.] Budd, D. Jenssen, and U. Radok. Polarforschung, Bd. 6, Jahrg. 39, Nr. 1, 1969, p. 293-306.

Grigoryan, S. S., and others. 1976. Mathematical model of a three-dimensional non-isothermal glacier, by S. S. Grigoryan, M. S. Krass, and P. A. Shumskiy. Journal of Glaciology, Vol. 17, No. 77, p. 401-1 7.

Nye, J. F. I95I. The flow of glaciers and ice-sheets as a problem in plasticity. Proceedings of the Royal Society of London, Ser. A, Vol. 207, No. 1091, p. 554-72.

Tolstikov, Ye. I., ed. I966. Atlas Antarktiki. I [Atlas of the Antarctic. I]. Moscow, Leningrad, Glavnoye Upravleniye Geodezii i Kartografii. 